\title{
An Atmospheric Teleconnection Linking ENSO and Southwestern European Precipitation
}

\section{Citation}

Shaman, Jeffrey, and Eli Tziperman. 2011. “An Atmospheric Teleconnection Linking ENSO and Southwestern European Precipitation." Journal of Climate 24 (1) (January): 124-139. doi:10.1175/2010jcli3590.1. http://dx.doi.org/10.1175/2010JCLI3590.1.

\section{Published Version}

doi:10.1175/2010jcli3590.1

\section{Permanent link}

http://nrs.harvard.edu/urn-3:HUL.InstRepos:11892638

\section{Terms of Use}

This article was downloaded from Harvard University's DASH repository, and is made available under the terms and conditions applicable to Other Posted Material, as set forth at http:// nrs.harvard.edu/urn-3:HUL.InstRepos:dash.current.terms-of-use\#LAA

\section{Share Your Story}

The Harvard community has made this article openly available.

Please share how this access benefits you. Submit a story.

\section{Accessibility}




\title{
An Atmospheric Teleconnection Linking ENSO and Southwestern European Precipitation
}

\author{
JEFFREY SHAMAN \\ College of Oceanic and Atmospheric Sciences, Oregon State University, Corvallis, Oregon \\ ELI TZIPERMAN \\ Department of Earth and Planetary Sciences, School of Engineering and Applied Sciences, \\ Harvard University, Cambridge, Massachusetts
}

(Manuscript received 22 December 2009, in final form 9 August 2010)

\begin{abstract}
Numerous studies have demonstrated statistical associations between the El Niño-Southern Oscillation (ENSO) and precipitation in the Mediterranean basin. The dynamical bases for these teleconnections have yet to be fully identified. Here, observational analyses and model simulations are used to show how ENSO variability affects rainfall over southwestern Europe (Iberia, Southern France, and Italy). A precipitation index for the region, named southwestern European Precipitation (SWEP), is used. The observational analyses show that ENSO modulates SWEP during the September-December wet season. These precipitation anomalies are associated with changes in large-scale atmospheric fields to the west of Iberia that alter low-level westerly winds and onshore moisture advection from the Atlantic.

The vorticity anomalies associated with SWEP variability are linked to ENSO through a stationary barotropic Rossby wave train that emanates from the eastern equatorial Pacific and propagates eastward to the Atlantic and Mediterranean. Solutions of the linearized barotropic vorticity equation produce such eastwardpropagating Rossby waves with trajectories that traverse the region of observed ENSO-related anomalies. In addition, these linearized barotropic vorticity equation solutions produce a dipole of positive and negative vorticity anomalies to the west of Iberia that matches observations and is consistent with the onshore advection of moisture. Thus, interannual variability of fall and early winter precipitation over southwestern Europe is linked to ENSO variability in the eastern Pacific via an eastward-propagating atmospheric stationary barotropic Rossby wave train.
\end{abstract}

\section{Introduction}

An association between precipitation in the Mediterranean region and the El Niño-Southern Oscillation (ENSO) has long been observed (Ropelewski and Halpert 1987; Dai and Wigley 2000; Rimbu et al. 2001; Mariotti et al. 2002; Park 2004). This ENSO-precipitation teleconnection manifests differently depending on the area of the larger Mediterranean region examined and the season in question.

For the Iberian Peninsula and North Africa, precipitation has been shown to increase during late summer,

Corresponding author address: Jeffrey Shaman, College of Oceanic and Atmospheric Sciences, Oregon State University, Corvallis, OR 97331.

E-mail: jshaman@coas.oregonstate.edu autumn, and early winter when El Niño conditions are present in the Pacific (Mariotti et al. 2002; Park 2004; Pozo-Vazquez et al. 2005; Vicente-Serrano 2005). However, during late winter and spring, precipitation is suppressed during an El Niño (Mariotti et al. 2002).

Seasonal lead-lag relationships have also been identified. Rodo et al. (1997) found an association between boreal winter ENSO conditions and precipitation over Spain during spring. Knippertz et al. (2003) found a similar relationship more broadly for southwestern Europe and North Africa. Both studies found that the strength and sign of this lead-lag relationship varied on decadal time scales. Others have found similar lead-lag associations (Laita and Grimalt 1997), and decadal variability of the ENSO teleconnection with precipitation in this region has been noted for contemporaneous associations as well (Mariotti et al. 2002; Park 2004). 
Studies have also documented associations between ENSO and precipitation over Italy and the central Mediterranean (Karagiannidis et al. 2008), as well as Israel, Turkey, and the eastern Mediterranean (Yakir et al. 1996; Price et al. 1998; Turkes 1998; Paeth and Friederichs 2004; Pozo-Vazquez et al. 2005).

Overall, associations between ENSO and Mediterranean precipitation have been described during all seasons of the year: boreal spring (Ropelewski and Halpert 1987; Rodo et al. 1997), summer (Ropelewski and Halpert 1987; Paeth and Friederichs 2004; Park 2004), autumn (Rodo et al. 1997; Mariotti et al. 2002; Park 2004), and winter (Price et al. 1998; Rimbu et al. 2001; Paeth and Friederichs 2004; Pozo-Vazquez et al. 2005; VicenteSerrano 2005; Sordo et al. 2008). It is difficult to determine whether the time and space discrepancies in the above studies are due to different teleconnection processes or result from a single teleconnection mechanism that produces different seasonal and regional effects. To resolve this, the dynamics of the ENSO-Mediterranean teleconnection must be understood. Unfortunately, understanding of the dynamics of the ENSO-Mediterranean teleconnection has not advanced much since Ropelewski and Halpert (1987) stated that the "implied ENSO relationships in these regions are difficult to understand or attribute to any of the known ENSO related atmospheric circulation changes."

One study (Park 2004), using correlation analysis, proposed that an eastward Rossby wave train emanating from the Pacific during late summer and autumn might be responsible for the changes over the Mediterranean; however, no further dynamical investigations have been published. Here, we investigate the dynamical basis of the teleconnection between ENSO and rainfall over the northwestern Mediterranean basin, including Iberia, Southern France, and Italy.

Section 2 describes the datasets used for this work. In section 3 , we examine the climatology of precipitation throughout the Mediterranean region. We then use composite analyses to identify where and when ENSO anomalies are most pronounced within the region. ENSOrelated precipitation anomalies are shown to be large during the September-December (SOND) rainy season over the northwestern Mediterranean. An index of precipitation, southwestern European precipitation (SWEP), is then defined and shown to be correlated with the Niño-3.0 index of SSTs but not the North Atlantic Oscillation (NAO).

Section 4 presents ENSO-based composites of SOND large-scale atmospheric fields, which reveal an anomalous vorticity dipole to the west of Iberia. This dipole advects moisture onshore during El Niño events. Singular value decomposition (SVD) of the vorticity and precipitation fields shows that ENSO-related covariability of SWEP and the vorticity field is the dominant mode of interannual variability in the region.

Section 5 presents solutions of the linearized barotropic vorticity equation, which show that ENSO-related changes in large-scale atmospheric fields, including the dipole west of Iberia, result from a stationary barotropic Rossby wave train that propagates eastward from the eastern equatorial Pacific. Section 6 presents discussion of the findings.

\section{Data}

Analyses of precipitation were performed using four different gridded monthly datasets: 1) 1979-2008 National Oceanographic and Atmospheric Administration (NOAA)/National Centers for Environmental Prediction (NCEP) Climate Anomaly Monitoring System (CAMS) Outgoing Longwave Radiation Precipitation Index (OPI; Janowiak and Xie 1999); 2) 1979-2008 National Aeronautics and Space Administration (NASA) Global Precipitation Climatology Project (GCPC) version 2.1 (Adler et al. 2003); 3) 1979-2008 NOAA/NCEP Climate Prediction Center (CPC) Merged Analysis of Precipitation (CMAP; Xie and Arkin 1997); and 4) 19492008 NCEP-NCAR reanalysis estimates (Kalnay et al. 1996). All four precipitation datasets are gridded at $2.5^{\circ} \times$ $2.5^{\circ}$ resolution. The CAMS OPI and NASA GCPC precipitation are both derived from satellite and gauge estimates. The CMAP precipitation is a merging of satellite estimates, gauge estimates, and numerical predictions. NCEP-NCAR reanalysis fields are generated from a combined model-observation assimilation construct; however, the precipitation field of this reanalysis is exclusively model determined.

Sea surface temperature averaged over the Niño-3.0 region $\left(5^{\circ} \mathrm{N}-5^{\circ} \mathrm{S}, 150^{\circ}-90^{\circ} \mathrm{W}\right)$ was the index of ENSO used for this study (Kaplan et al. 1998). The Niño-3.0 index was used for constructing ENSO-based composites of other fields. Specifically, for a given season [e.g., January-March (JFM), February-April (FMA), SOND, etc.], years for which the Niño -3.0 index was in excess of plus (El Niño) or minus (La Niña) one standard deviation were identified. For a specific field (e.g., precipitation), ENSO-based composites were then constructed by subtracting conditions for that season averaged for all La Niña years from conditions for that season averaged for all El Niño years.

In addition to precipitation, a number of additional 1949-2008 monthly NCEP-NCAR reanalysis atmospheric fields were composited, including relative vorticity, temperature, wind, and specific humidity. Reanalysis streamfunction fields were also used for experiments with a linearized barotropic vorticity equation model. 

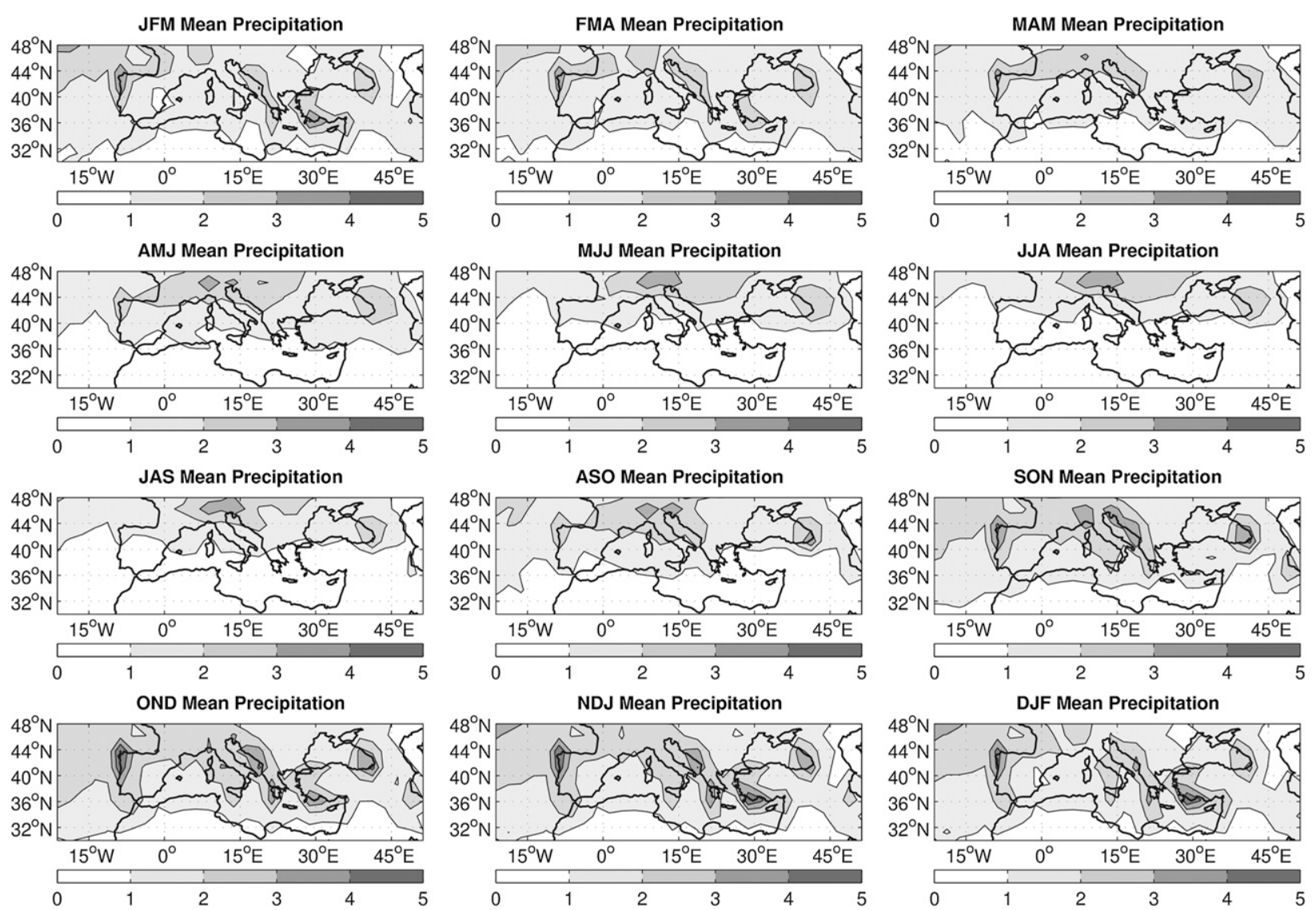

FIG. 1. Twelve 3-month running averages of 1979-2008 CAMS OPI estimates of precipitation. Units are $\mathrm{mm}^{\mathrm{day}}{ }^{-1}$. Contour interval is $1 \mathrm{~mm} \mathrm{day}^{-1}$.

The northwestern Mediterranean is proximate to the NAO, which has been shown to affect weather in the region (Ulbrich et al. 1999; Trigo et al. 2004; Santos et al. 2005; Paredes et al. 2006). Therefore, associations between the NAO and SWEP were also investigated. A 1950-2008 monthly index of the NAO (Climate Prediction Center 2009) was used for this effort. The NAO index values are derived using a rotated principal component analysis of 500-hPa geopotential height anomalies.

\section{Analyses of precipitation}

Figure 1 shows the 1979-2008 seasonal evolution of precipitation across the Mediterranean basin as estimated by running 3-month averages of CAMS OPI. Along the northwestern Mediterranean coast, in particular Iberia, southern France, and Italy, the lowest precipitation levels occur from May-July through July-September, and the highest precipitation levels are clearly in the fall and winter: September-November through DecemberFebruary. Analyses of the NASA GCPC, CMAP, and
NCEP-NCAR reanalysis estimates of precipitation reveal similar climatologies (not shown).

We next examined seasonal ENSO-based composites of CAMS precipitation (Fig. 2). The strongest ENSO response is along the west coast of Iberia and begins during the August-October season and extends through November-January. This evolution of ENSO-based anomalies suggests that modulation by ENSO is strongest for $36^{\circ}-48^{\circ} \mathrm{N}$ and $20^{\circ} \mathrm{W}-20^{\circ} \mathrm{E}$ during SOND, which is the bulk of the rainy season. This finding is consistent with previous works, which have noted a similar precipitation response to ENSO for this region during these months (Mariotti et al. 2002; Pozo-Vazquez et al. 2005).

The same region experiences negative ENSO-related anomalies 6-months earlier. This signal is weaker, but it encompasses a similar region during the February-April through May-July seasons. In addition, the northeastern Mediterranean, $36^{\circ}-48^{\circ} \mathrm{N}$ and $20^{\circ}-50^{\circ} \mathrm{E}$, shows a tendency to vary out of phase with the northwestern Mediterranean. In the northeastern region, negative ENSO-related anomalies are evident during the fall and early winter and 
JFM ENSO Composite

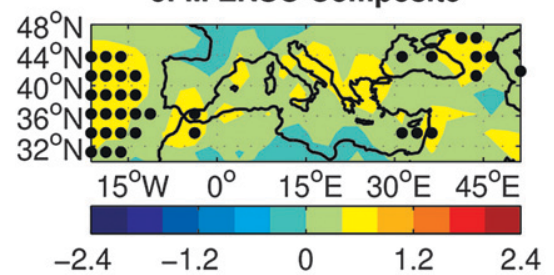

FMA ENSO Composite

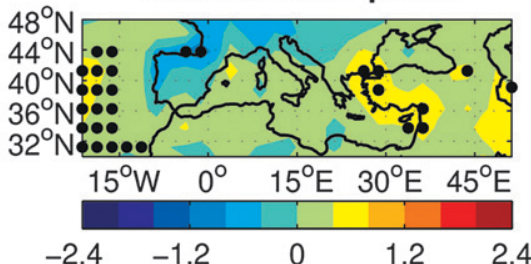

MAM ENSO Composite

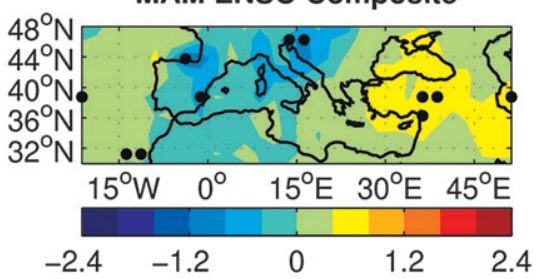

AMJ ENSO Composite

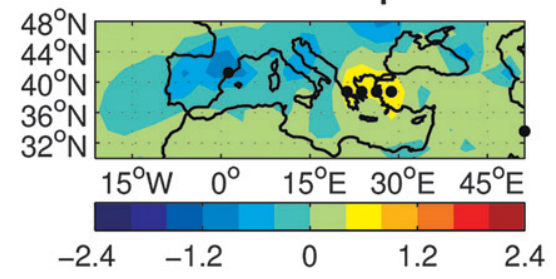

MJJ ENSO Composite

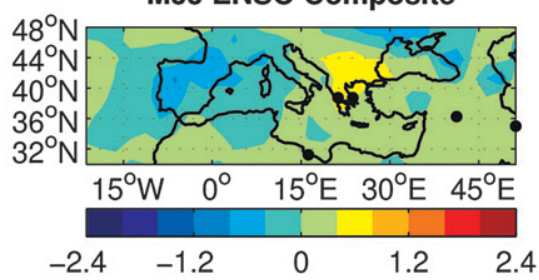

JJA ENSO Composite

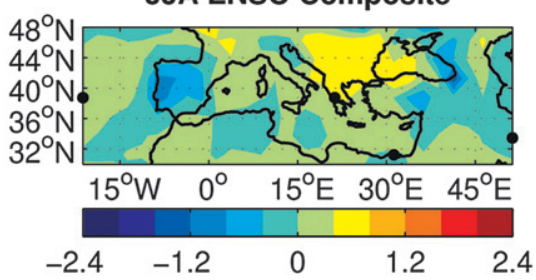

ASO ENSO Composite

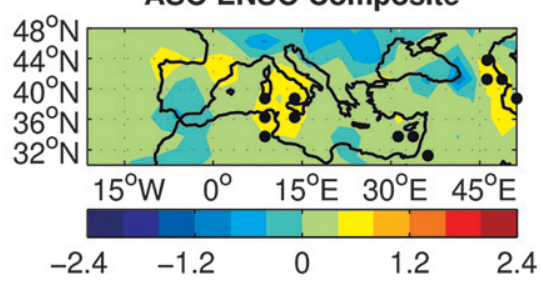

SON ENSO Composite

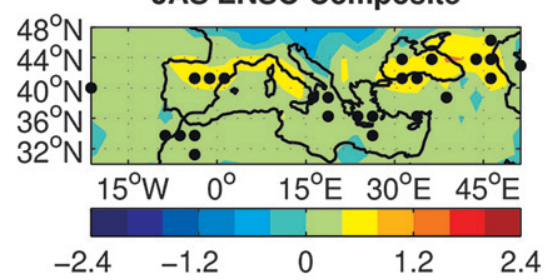

OND ENSO Composite

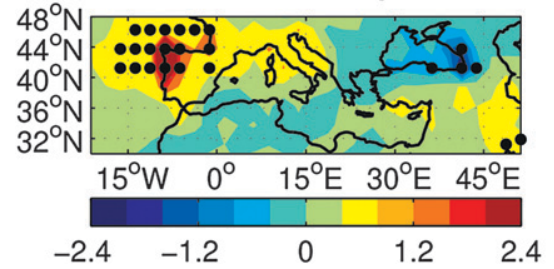

NDJ ENSO Composite

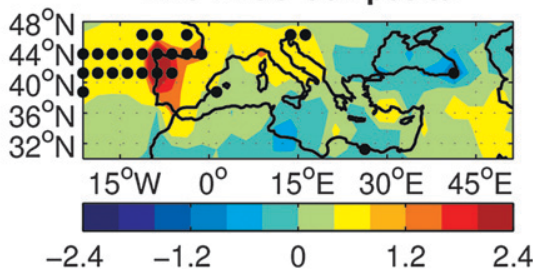

FIG. 2. 1979-2008 3-month seasonal ENSO-based composites of CAMS precipitation. Each subplot presents a composite for a different 3-month season (e.g., JFM, FMA, etc.). Units are $\mathrm{mm} \mathrm{day}^{-1}$. Color patch intervals are $0.4 \mathrm{~mm} \mathrm{day}{ }^{-1}$. Regions significant at the $95 \%$ level $(p<0.05)$ are dotted with black circles. Significance is based on bootstrap confidence intervals estimated by generation of 5000 random composite maps for each 3-month period.

positive anomalies during the spring and early summer. The NASA GCPC, CMAP, and NCEP-NCAR reanalysis estimates of precipitation all reveal similar patterns (not shown).

For this study we focus on precipitation over the northwestern Mediterranean. We define SWEP as the average precipitation for the region spanning $36^{\circ}-48^{\circ} \mathrm{N}$ and $20^{\circ} \mathrm{W}-$ $20^{\circ} \mathrm{E}$, which includes Iberia, France, and Italy. Figure 3 shows the SWEP climatology of 3-month seasonalaveraged precipitation for each of the four precipitation datasets. NASA GPCP precipitation rates are consistently greater than the other three datasets, which are in relative agreement; however, all four datasets depict a similar seasonal cycle in which the OND season is the period of maximum precipitation for this region.
An annual time series of SOND precipitation anomalies is also shown for each of the precipitation datasets. There is an apparent tendency for more precipitation during SOND El Niño years and less precipitation during SOND La Niña years. For instance, 1988 and 2007 were SOND La Niña years during which SWEP was very low. Conversely, 1982, 1987, 1997, and 2002 were all SOND El Niño years and these are years of high SOND SWEP. Only 1949 and 1999 stand out as SOND La Niña years with decidedly positive SWEP; similarly, 1972 and 1991 are the only SOND El Niño years with negative SWEP. Across all four datasets, SOND precipitation is on average $0.30 \mathrm{~mm} \mathrm{day}^{-1}$ above normal during El Niño and $0.30 \mathrm{~mm} \mathrm{day}^{-1}$ below normal during La Niña. 
SWEPI Climatologies

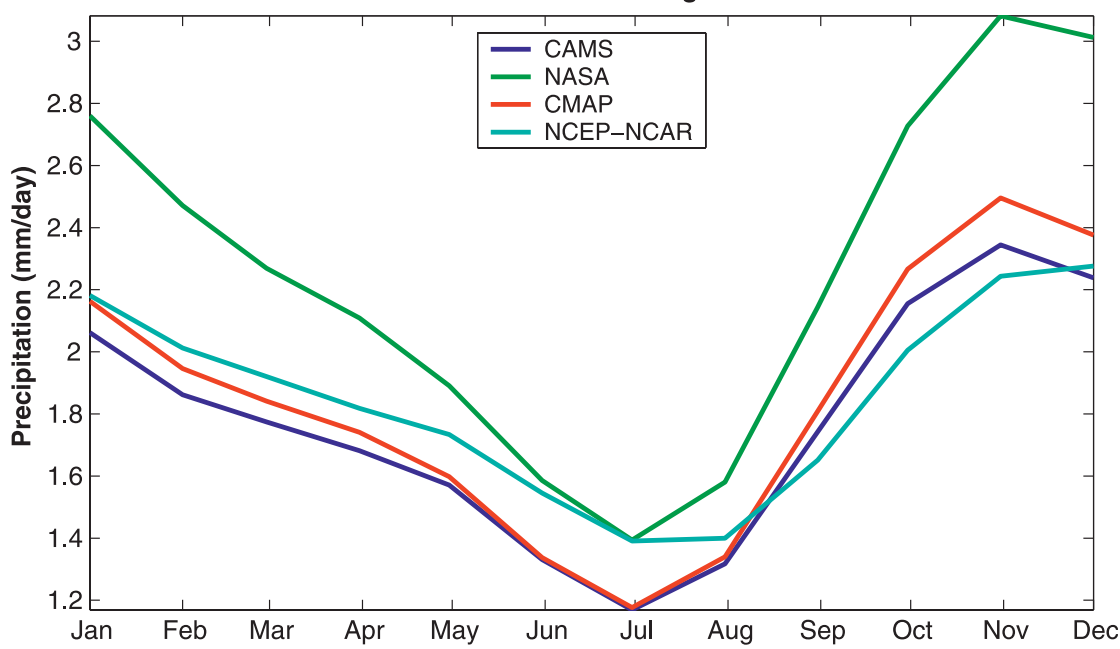

SOND SWEPI Precipitation Anomalies

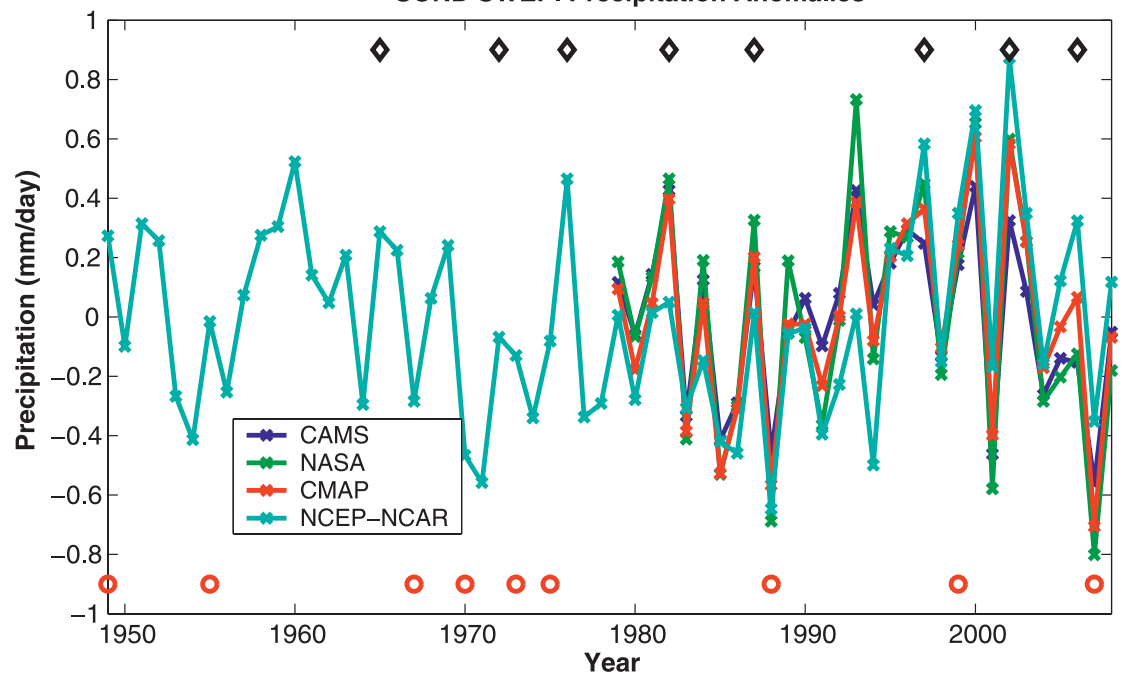

FIG. 3. (top) SWEP 3-month season climatologies. The monthly value corresponds to the middle month of a 3-month season (e.g., the February value is for January-March). Shown are the CAMS, NASA, CMAP, and NCEP-NCAR climatologies. (bottom) SWEP anomalies for SOND for each of the four precipitation datasets. Also shown are black diamonds for SOND El Niño years and red circles for SOND La Niña years ( \pm 1 std dev from Niño-3.0, respectively). Units are $\mathrm{mm}$ day $^{-1}$.

Table 1 shows the correlations of SOND SWEP, Niño-3.0, and the NAO. The correlations with Niño-3.0 are all statistically significant $(p<0.01)$ and show that SOND precipitation is linked with concurrent conditions in the equatorial Pacific. SOND SWEP correlations with the NAO only reach statistical significance $(p<0.05)$ for the reanalysis precipitation estimates. These results were found to be insensitive to the precise size of the SWEP domain; expansion or contraction of the domain by 5 degrees in any direction failed to alter these findings (Fig. 3 and Table 1). Similar results were also found using an alternate NAO index from the Climate Research Unit (Jones et al. 1997).

\section{Analyses of large-scale fields \\ a. ENSO-based composites}

Large-scale circulation changes can affect precipitation patterns in many ways. For example, changes to large-scale subsidence due to changes in the flow field may favor or disfavor some types of precipitation; alternatively, large-scale flow patterns may affect storm 
TABLE 1. Correlations of SOND SWEP derived from four different datasets (1979-2008 CAMS OPI, NASA, and CMAP and 19492008 NCEP-NCAR), the 1949-2008 SOND Niño-3.0 index, and the 1950-2008 SOND NAO index. Statistically significant correlations with the Niño-3.0 and NAO indices at $p<0.05$ are in bold and at $p<0.01$ have an asterisk.

\begin{tabular}{lccccrr}
\hline \hline & CAMS OPI & NASA & CMAP & NCEP-NCAR & Niño-3.0 & NAO \\
\hline CAMS OPI & 1.00 & 0.96 & 0.95 & 0.67 & $\mathbf{0 . 4 1}^{*}$ & -0.04 \\
NASA & 0.96 & 1.00 & 0.96 & 0.74 & $\mathbf{0 . 4 2}^{*}$ & -0.07 \\
CMAP & 0.95 & 0.96 & 1.00 & 0.85 & $\mathbf{0 . 4 4}^{*}$ & -0.14 \\
NCEP-NCAR & 0.67 & 0.74 & 0.85 & 1.00 & $\mathbf{0 . 3 5}^{*}$ & $-\mathbf{0 . 3 1}$ \\
Niño-3.0 & $\mathbf{0 . 4 1 *}$ & $\mathbf{0 . 4 2} *$ & $\mathbf{0 . 4 4}^{*}$ & $\mathbf{0 . 3 5} *$ & 1.00 & 0.08 \\
NAO & -0.04 & -0.06 & -0.14 & $-\mathbf{0 . 3 1}$ & 0.08 & 1.00 \\
\hline
\end{tabular}

steering and moisture advection (e.g., from the Atlantic to the mountainous Iberian Peninsula).

As precipitation anomalies may develop for different reasons, some care must be taken when attempting to identify the physical mechanism linking ENSO-related changes of large-scale atmospheric conditions and local precipitation response. To investigate these potential linkages, we initially examined ENSO-based composites of various atmospheric fields.

Figure 4 shows the ENSO composite of $200-\mathrm{hPa}$ relative vorticity for the SOND season. A positive vorticity anomaly within the North African-Asian (NAA) jet is clearly evident from $15^{\circ} \mathrm{N}, 70^{\circ} \mathrm{W}$ to $30^{\circ} \mathrm{N}, 50^{\circ} \mathrm{E}$. This response of the NAA jet to ENSO has previously been described for both boreal winter (Shaman and Tziperman 2005) and summer (Shaman and Tziperman 2007; Shaman et al. 2009). In addition, a Rossby wave train of alternating positive and negative vorticity anomalies emanating from the equatorial Pacific and extending over North America to the Atlantic and SWEP region is evident. A similar wave train has been described for boreal winter (Shaman and Tziperman 2005).

A north-south dipole vorticity anomaly over the Atlantic just off the European and North African coasts appears in the ENSO composite. The positive lobe is centered just southwest of Ireland $\left(15^{\circ} \mathrm{W}, 50^{\circ} \mathrm{N}\right)$; the negative lobe is just west of the Straits of Gibraltar $\left(15^{\circ} \mathrm{W}, 35^{\circ} \mathrm{N}\right)$. These anomalies are not dissimilar from the positive phase of the NAO, though they are shifted south and east of the canonical position of the NAO dipole.

The vorticity anomalies extend throughout the troposphere and possess an equivalent barotropic structure (Figs. 5a,b), which is consistent with an extratropical Rossby wave disturbance that has emanated from the deep tropics (Hoskins and Karoly 1981). These vorticity anomalies are accompanied by increased westerlies over the Atlantic and Iberia at $40^{\circ} \mathrm{N}$ (Figs. $5 \mathrm{c}, \mathrm{d}$ ).

The vorticity and wind anomalies increase onshore moisture advection from the Atlantic during SOND El Niño events (Figs. 5e,f). Zonal moisture advection on a given pressure level is defined as $u q$, where $u$ is the zonal wind, and $q$ is specific humidity. These moisture advection anomalies extend throughout the troposphere (only 850 and $500 \mathrm{hPa}$ are shown). Mariotti et al. (2002) found a similar moisture flux response to ENSO during boreal autumn. Non-ENSO related variability of wintertime onshore humidity advection has also been associated with precipitation rate changes in this region (Zhang et al. 1997; Ulbrich et al. 1999).

Thus, it appears that increased southwestern European precipitation during El Niño, particularly over Iberia, results from increased moisture advection from the Atlantic, which is set up by large-scale flow changes in the region. Westerly winds predominate at this latitude; as a consequence, the increased moisture advection not only affects precipitation over Iberia but regions as far downstream as Italy. In addition, air column water vapor that precipitates over Iberia may also be recycled via evaporation from the land surface and continued eastward advection and thus contribute to precipitation increases farther downstream.

We also examined ENSO-related changes in lowertropospheric static stability as measured by the difference in equivalent potential temperature between the 500- and 925-hPa levels. Changes in static stability can affect some precipitation forms and have been shown to be of relevance to the variability of precipitation over the eastern Mediterranean (Eshel and Farrell 2000, 2001). While there is evidence of stability changes over the SWEP region, specifically, decreased stability during El Niño (not shown), these anomalies are small and biased to the north of the largest SOND ENSO-related precipitation anomalies (Fig. 2). It thus appears that onshore moisture advection plays a more dominant role creating SWEP region precipitation anomalies than changes in lower-tropospheric stability.

\section{b. NAO composites}

The NAO is known to affect North Atlantic storm tracking and European weather (Rogers 1997; Trigo 


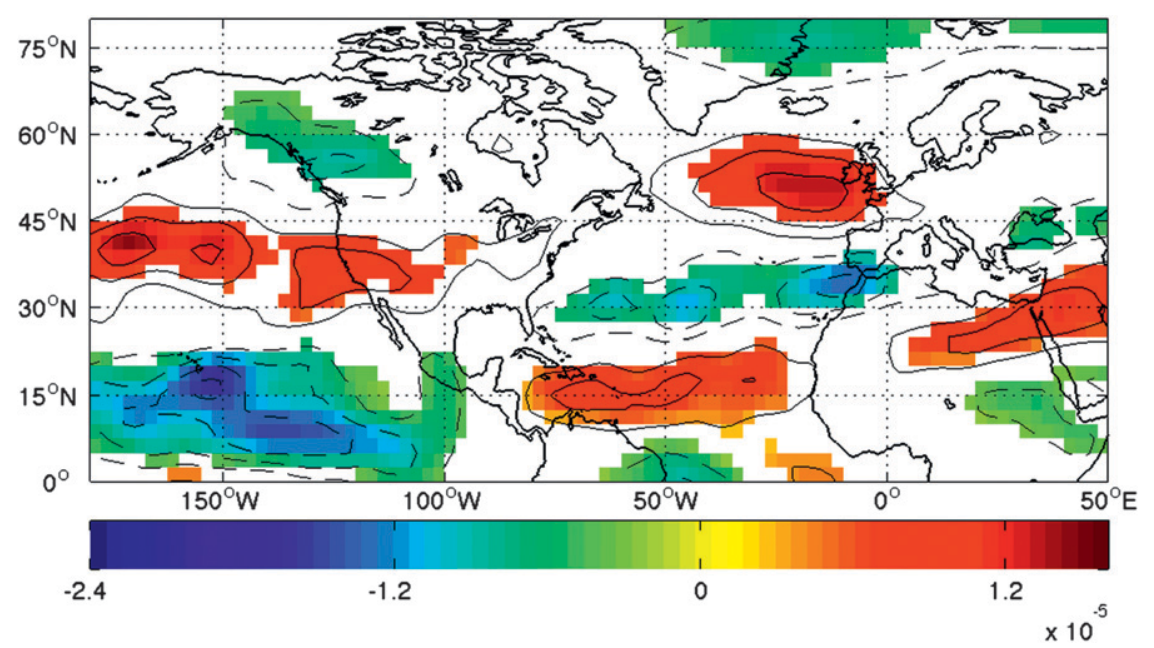

FIG. 4. ENSO composite of 200-hPa SOND NCEP-NCAR reanalysis relative vorticity. El Niño minus La Niña compositing is based on \pm 1 standard deviation of the Niño-3.0 index. Contour interval is $0.4 \times 10^{-5} \mathrm{~s}^{-1}$. The zero contour is omitted. Colored areas denote regions significant at the $95 \%$ level $(p<0.05)$, based on bootstrap confidence intervals estimated by generation of 5000 random composite maps for the SOND period.

et al. 2002; Santos et al. 2007), including precipitation rates over Iberia (Rodo et al. 1997; Ulbrich et al. 1999; Trigo et al. 2004; Santos et al. 2005; Paredes et al. 2006). To distinguish ENSO variability from the variability of the NAO, we composited 200- and 500-hPa NCEPNCAR reanalysis relative vorticity using NAO index values averaged for SOND (Fig. 6). Years for which the SOND NAO index was greater than one standard deviation were classified as positive, and years less than one standard deviation were classified as negative. NAO-based composites were then constructed by subtracting vorticity conditions averaged for all negative years from conditions averaged for all positive years.

Unlike the ENSO-based composite, the NAO-based composite reveals no clear wave train emanating from the Pacific. The strongest vorticity anomalies are farther north and west than for the ENSO composite, stretch farther east-west across the Atlantic, and reflect the intensification of the North Atlantic stormtrack during the positive phase of the NAO. These anomalies are too far north to direct storms or moisture onshore to Iberia but instead are associated with increased storm tracking toward the British Isles.

Farther south, the vorticity anomalies indicate that the negative phase of the NAO does favor onshore flow to the Iberian Peninsula during SOND, as has been shown for boreal winter (Rodo et al. 1997; Ulbrich et al. 1999; Trigo et al. 2004; Santos et al. 2005). However, it is clear that the large-scale spatial features associated with NAO variability are dissimilar from those related to ENSO (Fig. 4). Furthermore, and as shown in Table 1, the temporal variability of SOND NAO and ENSO are not related, nor is SOND NAO as well correlated with SWEP as ENSO.

It also should be noted that the NAA jet responses to the NAO and ENSO are dissimilar. For the NAO, the vorticity anomaly extending over the North Atlantic from $15^{\circ}-30^{\circ} \mathrm{N}$ is roughly collocated with NAA jet (Fig. 6); however, these anomalies are in fact displaced slightly north of the vorticity anomalies evident in the ENSO composite (Fig. 4). In addition, these NAO composite anomalies do not extend east of $40^{\circ} \mathrm{E}$, whereas for the ENSO composites single-signed vorticity anomalies are evident along the entire NAA jet core from the North Atlantic to the North Pacific (not shown).

\section{c. Singular value decomposition}

The preceding results indicate that SWEP variability seems best associated with ENSO-related equivalent barotropic vorticity and onshore moist advection anomalies. Using 200-hPa SOND reanalysis relative vorticity and CAMS OPI precipitation we next performed SVD to determine if the dominant mode of interannual covariability among these two fields would yield spatial loading patterns similar to the ENSO composites of precipitation and relative vorticity.

Here, the SVD analysis derives pairs of spatial patterns from the combined covariance matrix of the relative vorticity and precipitation fields. This linear decomposition is simply principal component analysis 
a) SOND ENSO 500hPa $\zeta$ Composite

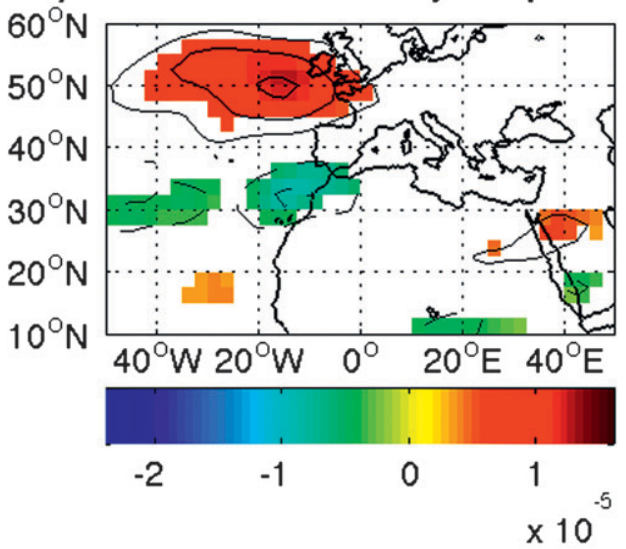

c) SOND ENSO 500hPa U Composite

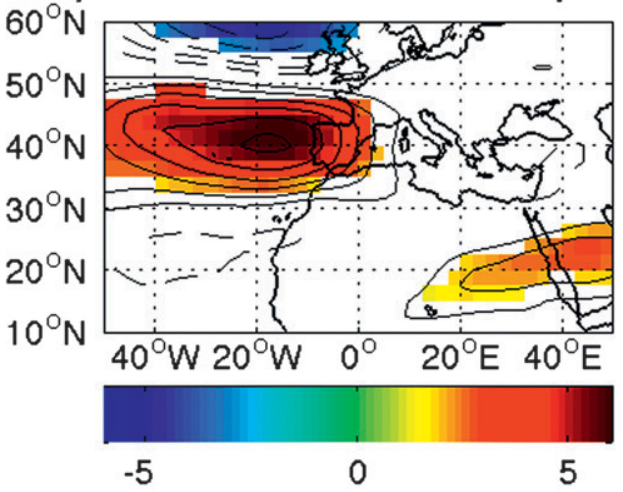

e) SOND ENSO Composite $500 \mathrm{hPa}$ Zonal Moisture Advection

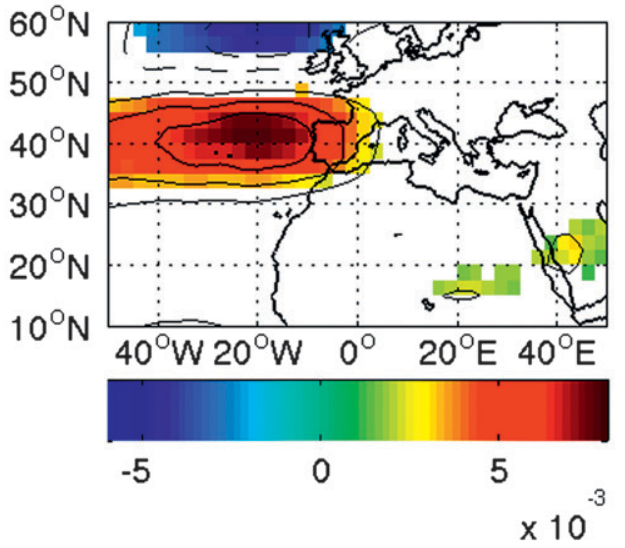

b) SOND ENSO $850 \mathrm{hPa} \zeta$ Composite

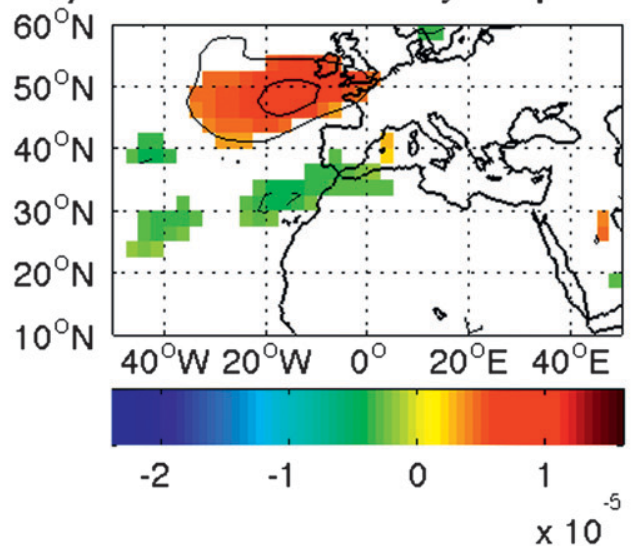

d) SOND ENSO $850 \mathrm{hPa} U$ Composite

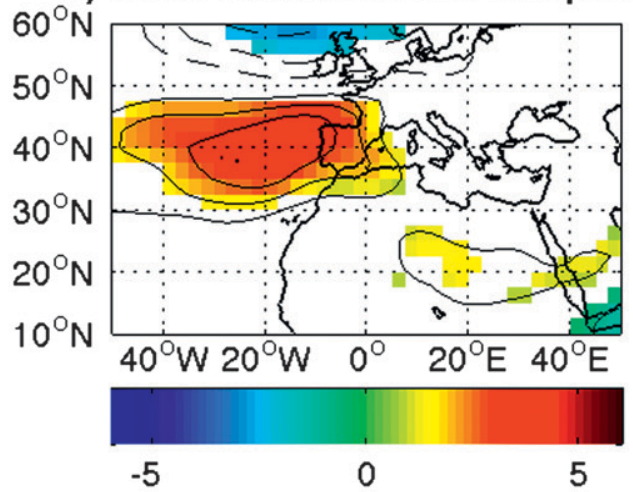

f) SOND ENSO Composite $850 \mathrm{hPa}$ Zonal Moisture Advection

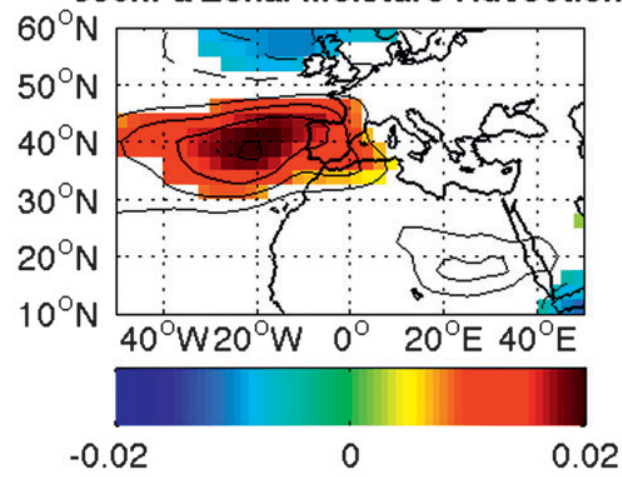

FIG. 5. 500-hPa SOND NCEP-NCAR reanalysis ENSO composites of (a) relative vorticity, (c) zonal wind, and (e) zonal moisture advection. (b),(d),(f) The same composite metrics as in (a),(c),(e) but at $850 \mathrm{hPa}$ are shown. Units are (a),(b) $\mathrm{s}^{-1}$; (c),(d) $\mathrm{m} \mathrm{s}^{-1}$; and (e),(f) $\left[\left(\mathrm{kg} \mathrm{kg}^{-1}\right)\left(\mathrm{m} \mathrm{s}^{-1}\right)\right]$. Contour intervals are (a),(b) $0.4 \times 10^{-5} \mathrm{~s}^{-1}$; (c), (d) $1 \mathrm{~m} \mathrm{~s}^{-1}$; (e) $0.002\left[\left(\mathrm{~kg} \mathrm{~kg}^{-1}\right)\left(\mathrm{m} \mathrm{s}^{-1}\right)\right]$; and (f) $0.005\left[\left(\mathrm{~kg} \mathrm{~kg}^{-1}\right)\left(\mathrm{m} \mathrm{s}^{-1}\right)\right]$. The zero contour is omitted in all plots. Colored regions denote statistical significance as in Fig. 4. 

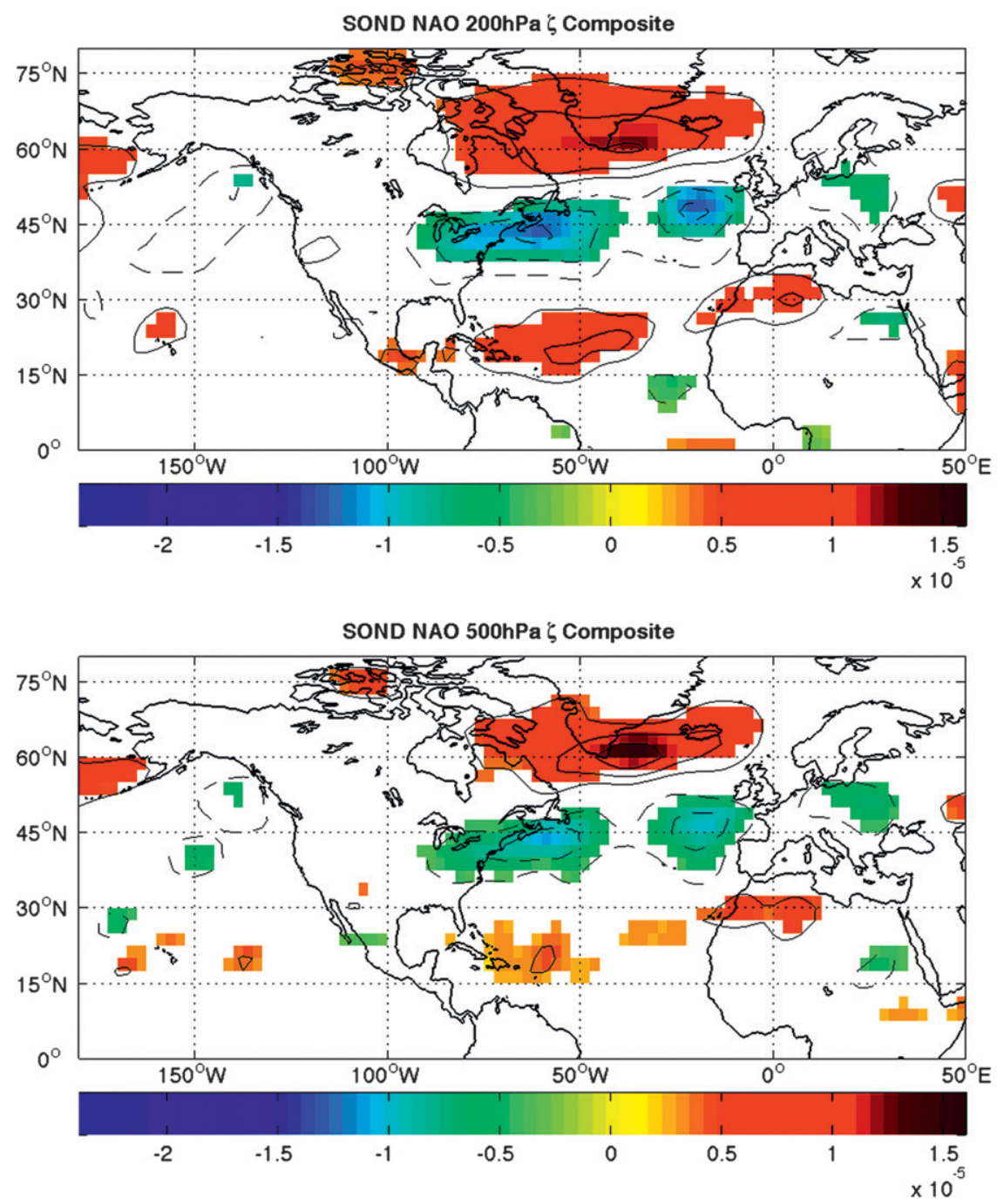

FIG. 6. NAO-based composites of 200- and 500-hPa SOND NCEP-NCAR reanalysis relative vorticity. Positive minus negative phase compositing is based on \pm 1 standard deviation of the NAO index. Contour interval is $0.4 \times 10^{-5} \mathrm{~s}^{-1}$. The zero contour is omitted. Colored regions denote statistical significance as in Fig. 4.

performed on the two fields when first combined in one spatial-temporal matrix. Bretherton et al. (1992) referred to this method as combined principal component analysis.

Figure 7 shows the leading mode derived for domains of $50^{\circ} \mathrm{W}-50^{\circ} \mathrm{E}$ and $10^{\circ}-60^{\circ} \mathrm{N}$ for the vorticity field and $20^{\circ} \mathrm{W}-20^{\circ} \mathrm{E}$ and $36^{\circ}-48^{\circ} \mathrm{N}$ (i.e., the SWEP region) for the CAMS OPI precipitation field. This leading mode represents $31.5 \%$ of the total variance, and its spatial structure matches the ENSO composited anomalies of both precipitation and vorticity. In the vorticity field, both the dipole that brings moisture ashore to Iberia and the NAA jet anomalies are captured. In addition, the sense of the spatial fields (more precipitation associated with this vorticity structure) is consistent with the composite analysis.

For all four precipitation datasets, the leading mode of variability has a similar loading pattern and represents between $23 \%$ and $32 \%$ of total variability. This result is insensitive to the precise domain size of either the precipitation or vorticity fields. We also performed an alternate form of SVD using the cross-covariance matrix of the precipitation and relative vorticity fields (per Bretherton et al. 1992); this alternate decomposition analysis yielded similar results. Consequently, the SVD analysis supports the composite findings and suggests a coupling of ENSOmediated upper-tropospheric vorticity with rainfall anomalies over southwestern Europe during the SOND season. 

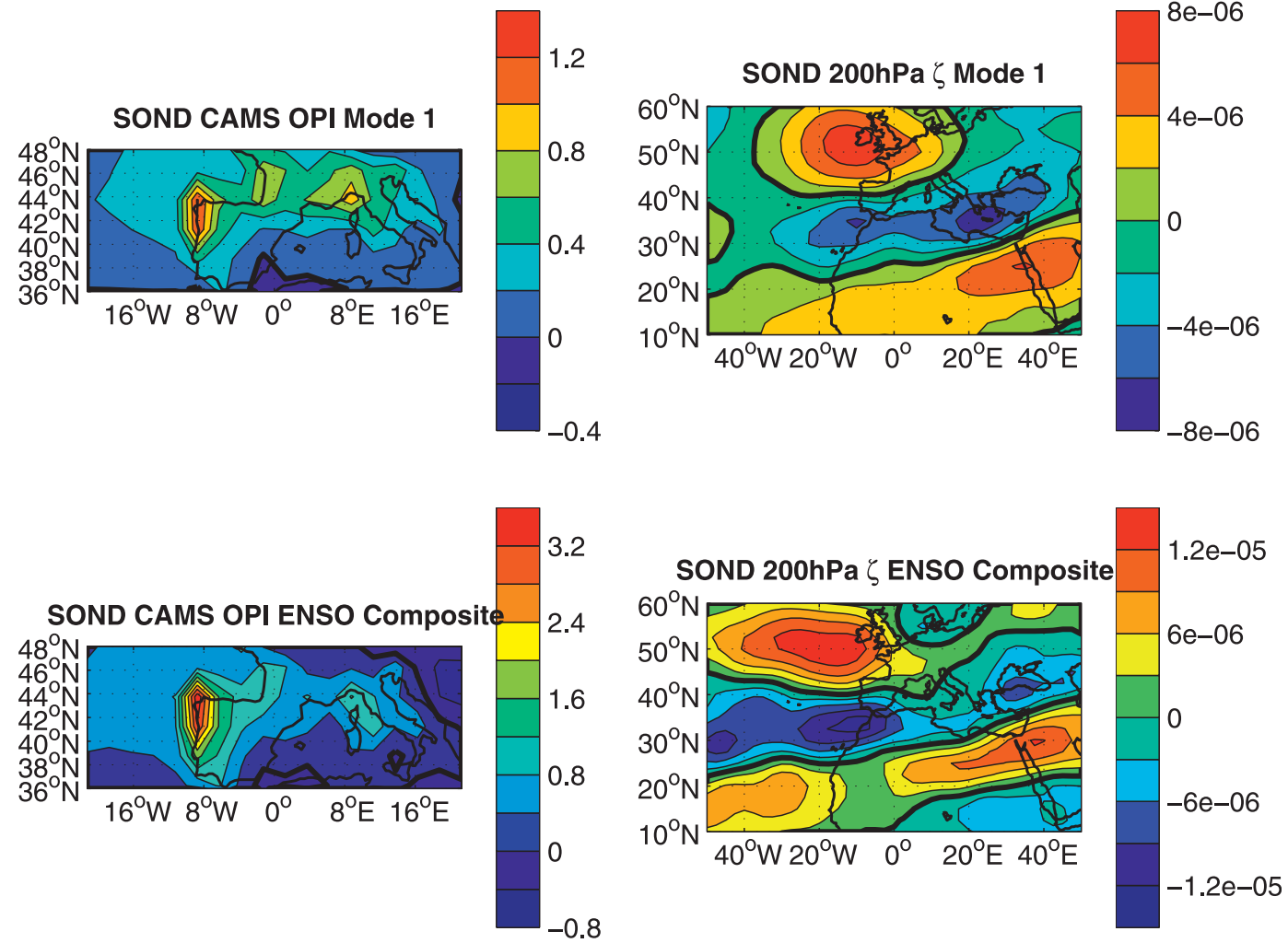

FIG. 7. (top) Leading mode derived from SVD of SOND CAMS precipitation and 200-hPa SOND reanalysis relative vorticity. This mode represents $31.5 \%$ of the total variance. Field domains are $50^{\circ} \mathrm{W}-50^{\circ} \mathrm{E}$ and $10^{\circ}-60^{\circ} \mathrm{N}$ for the vorticity field and $20^{\circ} \mathrm{W}-20^{\circ} \mathrm{E}$ and $36^{\circ}-48^{\circ} \mathrm{N}$ (i.e., the SWEP region) for the CAMS precipitation field. (bottom) ENSO composites of SOND CAMS precipitation and 200-hPa SOND reanalysis relative vorticity. Bottom panel contour intervals are (left) $0.4 \mathrm{~mm} \mathrm{day}^{-1}$ and (right) $0.3 \times 10^{-5} \mathrm{~s}^{-1}$. In all plots the zero contour is thickened.

\section{The teleconnection mechanism}

To investigate the dynamical underpinnings of the ENSO-southwestern Europe teleconnection, we used forced solutions of the linearized barotropic vorticity equation. This tool is adept at identifying stationary barotropic Rossby wave activity in a prescribed climatological atmosphere. The barotropic vorticity equation model was first linearized about a low-pass-filtered (zonal wavenumbers 0-8) 1949-2008 reanalysis climatology of SOND 200-mb streamfunction. The equation to be solved is then

$$
J\left(\bar{\psi}, \nabla^{2} \psi^{\prime}\right)+J\left(\psi^{\prime}, \nabla^{2} \bar{\psi}+f\right)+\alpha \nabla^{2} \psi^{\prime}+K \nabla^{4} \nabla^{2} \psi^{\prime}=R,
$$

where $\psi$ is the streamfunction, $f$ is the Coriolis force, $\alpha$ is the Rayleigh coefficient, $K$ is a diffusion coefficient, $R$ is a forcing function,

$$
J(A, B)=\frac{1}{r^{2}}\left(\frac{\partial A}{\partial \lambda} \frac{\partial B}{\partial \mu}-\frac{\partial A}{\partial \mu} \frac{\partial B}{\partial \lambda}\right)
$$

is the Jacobian, $\lambda$ is longitude, $\mu=\sin (\theta), \theta$ is latitude, and $r$ is the earth's radius. Here, the overbars indicate SOND time-mean flow (the basic state); primes signify the perturbation flow to be solved; $\alpha$ was set to $1.57 \times$ $10^{-6} \mathrm{~s}^{-1}$ [an $e$-folding time of $1 /(7$ days $)$ ]; and $K$ was set to $2.34 \times 10^{16} \mathrm{~m}^{4} \mathrm{~s}^{-1}$.

A forcing function was used to represent anomalous El Niño-related divergent forcing over the equatorial Pacific and was applied as

$$
R=-\left(f+\nabla^{2} \bar{\psi}\right) D
$$

where $D=3 \times 10^{-6} \mathrm{~s}^{-1}$. The appropriate forcing region was identified by generating ENSO composites of SOND precipitation for the equatorial Pacific. The three satellite datasets (CAMS OPI, NASA, and CMAP) were in general agreement with positive precipitation anomalies in the area of $150^{\circ} \mathrm{E}-90^{\circ} \mathrm{W}$ and $0^{\circ}-10^{\circ} \mathrm{N}$, as well as anomalies south of the equator over $0^{\circ}-12^{\circ} \mathrm{S}$ and $150^{\circ} \mathrm{E}-$ $150^{\circ} \mathrm{W}$ (Fig. 8). We therefore initially applied divergent forcing for this combined region. The model was run at T24 and solved for a steady solution, per the methods of Branstator (1983). 
a) NASA Precipitation Composite

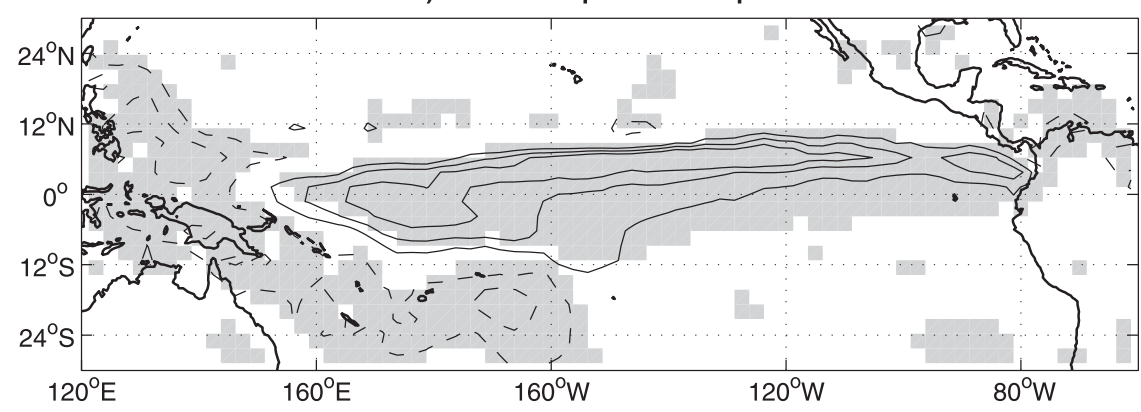

b) CMAP Precipitation Composite

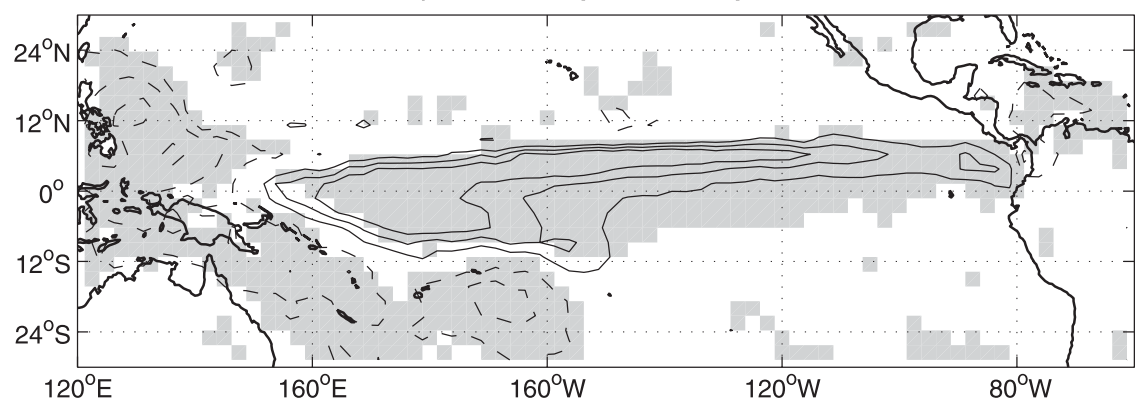

c) CAMS Precipitation Composite

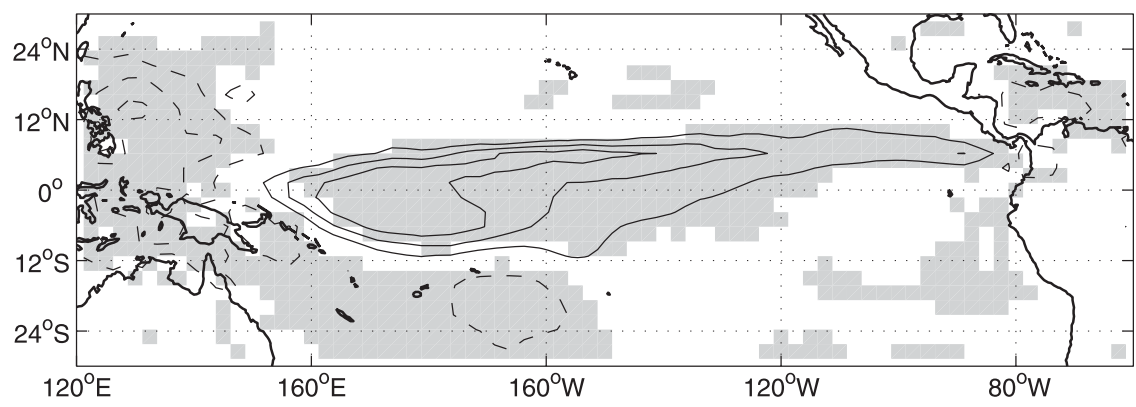

FIG. 8. ENSO composites of SOND precipitation estimates for the equatorial Pacific using (a) NASA GCPC version 2.1; (b) CMAP; and (c) CAMS OPI. El Niño minus La Niña compositing is based on \pm 1 standard deviation of the Niño-3.0 index. Contour interval is $2 \mathrm{~mm} \mathrm{day}{ }^{-1}$. The zero contour is omitted. Shaded areas denote regions significant at the $95 \%$ level $(p<0.05)$, based on bootstrap confidence intervals estimated by generation of 5000 random composite maps for the SOND period.

Figure 9 shows the solution for this forcing. The model vorticity solution captures the wave train propagating north and east and arcing over North America. This Rossby wave response appears to emanate from the eastern portion of the forcing region. The pattern generally matches the ENSO vorticity composite (Fig. 4); in particular, the dipole off the Iberian coast is captured. The nondivergent wind associated with these vorticity anomalies (Fig. 9c), as well as the equivalent barotropic structure of Rossby waves escaping from the tropics to the extratropics (Hoskins and Karoly 1981), suggest that this Rossby wave train produces low-level anomalous westerlies at $40^{\circ} \mathrm{N}$ over the Atlantic and Iberia during an SOND El Niño event.
We next ran the vorticity equation model with forcing over only the west-central Pacific (i.e., $150^{\circ} \mathrm{E}-150^{\circ} \mathrm{W}$, $10^{\circ} \mathrm{S}-10^{\circ} \mathrm{N}$, Figs. $\left.10 \mathrm{a}, \mathrm{b}\right)$. This produced a Pacific-North America (PNA)-style pattern but no vorticity response in the NAA jet and no dipole near Iberia; however, this forcing does contribute weakly to the positive node of the dipole $\left(15^{\circ} \mathrm{W}, 50^{\circ} \mathrm{N}\right)$.

Forcing over the east-central region (i.e., $150^{\circ}-90^{\circ} \mathrm{W}$ and $0^{\circ}-10^{\circ} \mathrm{N}$, Figs. $\left.10 \mathrm{c}, \mathrm{d}\right)$ produces the dipole response, a much stronger westerly nondivergent wind anomaly over Iberia (not shown) and the NAA jet response. These model results indicate that anomalous rainfall and divergence over the equatorial Pacific from $150^{\circ}-90^{\circ} \mathrm{W}$ and $0^{\circ}-10^{\circ} \mathrm{N}$ is crucial for the ENSO-southwestern Europe teleconnection. 
a) $\zeta^{\prime}$ solution

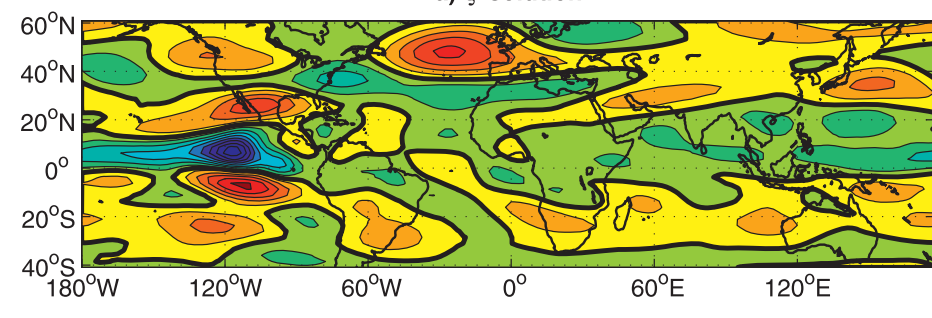

b) Model Forcing

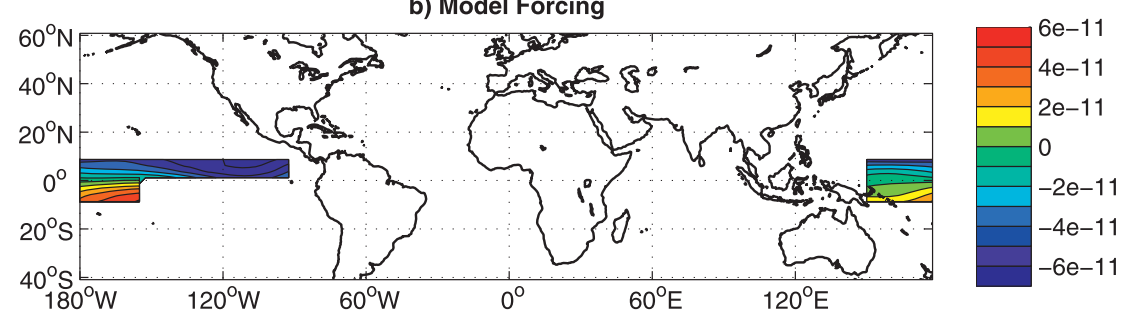

c) $\mathbf{u}^{\prime}$ solution

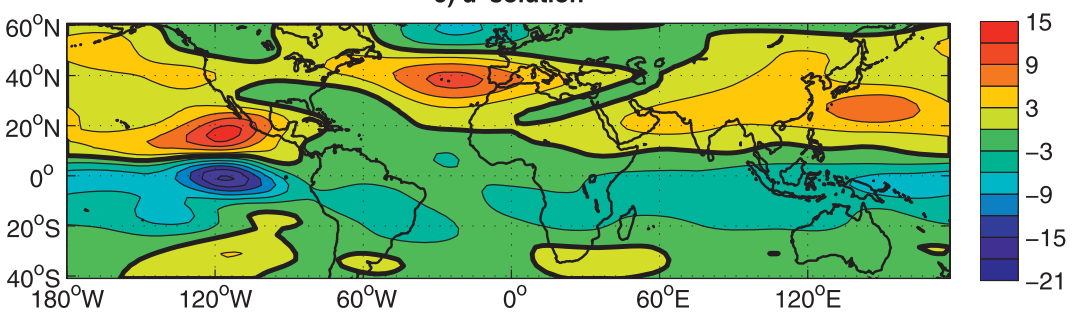

FIG. 9. Steady solutions of the linearized barotropic vorticity equation linearized about SOND 200-mb reanalysis climatology and forced with divergence extending over $150^{\circ} \mathrm{E}-$ $150^{\circ} \mathrm{W}, 10^{\circ} \mathrm{S}-10^{\circ} \mathrm{N}$, and $150-90^{\circ} \mathrm{W}$ and $0-10^{\circ} \mathrm{N}$. (a) Vorticity solution, (b) forcing $R$, and (c) nondivergent zonal wind derived from the vorticity solution are shown. Contour intervals are (a) $0.4 \times 10^{-5} \mathrm{~s}^{-1}$ and (c) $3 \mathrm{~m} \mathrm{~s}^{-1}$. The zero contour is thickened in both the top and bottom plots.
Integration with a time-marching form of the linearized barotropic vorticity equation model, using the eastcentral forcing region (Fig. 10d), shows the eastward propagation of the vorticity disturbance from the Pacific (Fig. 11). By day 4 of the integration, the positive node of the dipole has begun to develop. The weaker negative node develops around day 7. Positive vorticity anomalies within the NAA jet also develop, but these anomalies appear to derive from a westward-propagating anomaly within the jet, as has been shown for boreal summer and early fall (Shaman and Tziperman 2007; Shaman et al. 2009).

In addition, we applied damping at $150^{\circ} \mathrm{E}$ within the steady-state linearized barotropic vorticity equation, which inhibits Rossby wave propagation westward from the equatorial Pacific forcing region, per the methods described in Shaman and Tziperman (2007). This solution still produced the eastward stationary barotropic Rossby wave train and vorticity dipole west of Iberia, though it is slightly weakened (Fig. 12). The NAA jet response, however, is corrupted, which again indicates that this response is the result of westward Rossby wave propagation.
Thus, the NAA jet response appears not to be critical for SWEP response to ENSO; rather, the eastwardpropagating Rossby wave train is primarily responsible for the vorticity dipole over the North Atlantic.

\section{Discussion}

We find that ENSO modulates wet season precipitation levels over the northwestern Mediterranean basin. Specifically, increased convection over the eastern equatorial Pacific between $150^{\circ}-90^{\circ} \mathrm{W}$ and $0^{\circ}-10^{\circ} \mathrm{N}$, associated with September-December El Niño conditions, produces anomalous divergence in the upper troposphere that initiates an eastward- and northward-propagating stationary barotropic Rossby wave train. This Rossby wave train propagates over North America to the North Atlantic where it produces a dipole of anomalous vorticity off the European and North African coasts. As predicted by Rossby wave theory, the resultant wave train and dipole anomalies have an equivalent barotropic structure that projects to the lower troposphere. 
a) $\zeta^{\prime}$ solution: West-Central Forcing

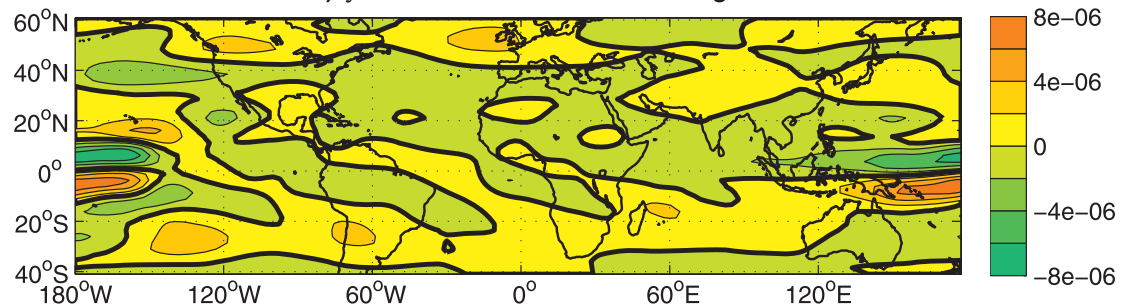

b) Model Forcing: West-Central Pacific

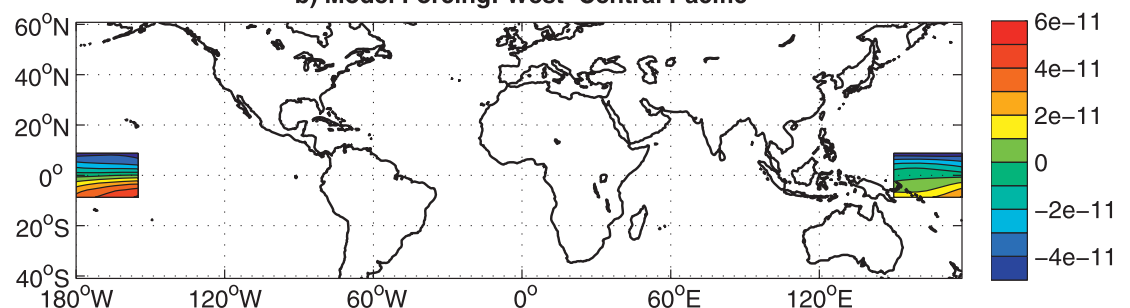

c) $\zeta^{\prime}$ solution: East-Central Forcing

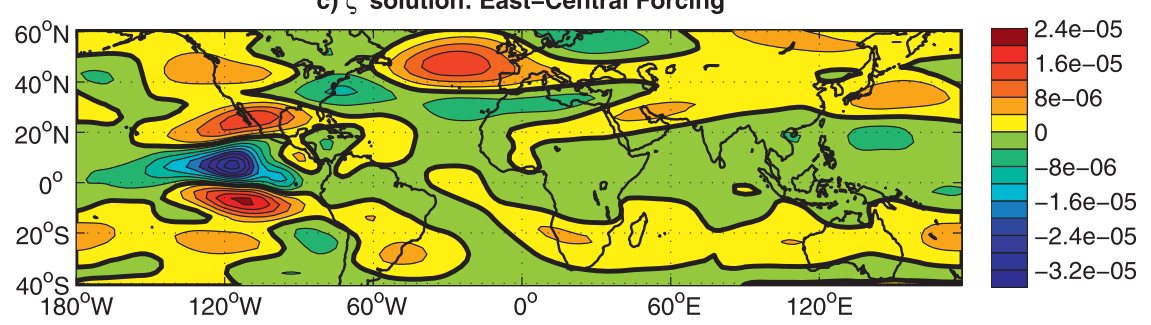

d) Model Forcing: East-Central Pacific

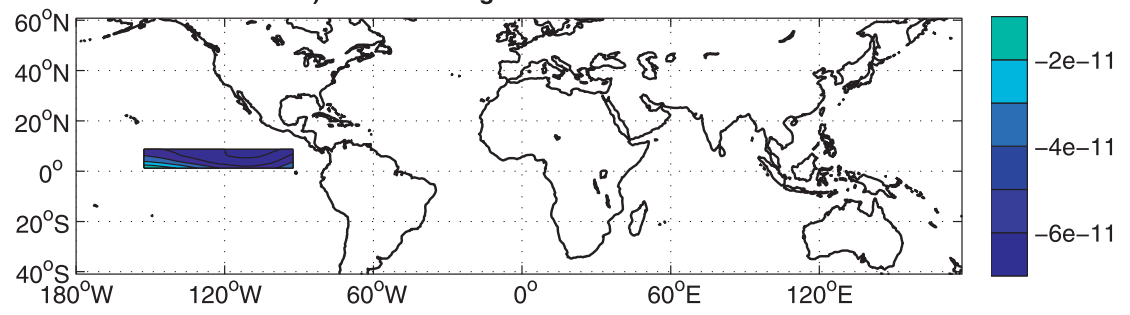

FIG. 10. Steady solutions of the linearized barotropic vorticity equation linearized about SOND 200-mb reanalysis climatology. (a) Vorticity solution to forcing at $150^{\circ} \mathrm{E}-150^{\circ} \mathrm{W}, 10^{\circ} \mathrm{S}-$ $10^{\circ} \mathrm{N}$, as shown in (b); (c) vorticity solution to forcing at $150^{\circ}-90^{\circ} \mathrm{W}$ and $0^{\circ}-10^{\circ} \mathrm{N}$ as shown in (d). Contour intervals are (a) $0.2 \times 10^{-5} \mathrm{~s}^{-1}$ and (c) $0.4 \times 10^{-5} \mathrm{~s}^{-1}$. In both (a) and (c) the zero contour is thickened.

The lower-level vorticity anomalies associated with the dipole increase onshore moisture advection from the Atlantic to the Iberian Peninsula. This onshore moisture advection produces increased precipitation, particularly upon encountering mountainous terrain, as far downstream as Italy. Thus, the September-December teleconnection between ENSO and northwestern Mediterranean precipitation is mediated by an atmospheric Rossby wave train that alters conditions over the Atlantic Ocean.

The effect of SOND ENSO variability on southwestern European precipitation is not uniform. The strongest response occurs over the western coastal mountainous portion of Iberia, where anomalous moisture is first advected onshore (Fig. 7). Over the rest of the SWEP region (eastern Iberia, southern France, and Italy), precipitation still increases in response to SOND El Niño conditions; however, the response is less marked. A secondary maximum is evident over the Ligurian Sea, which is possibly associated with the coastal mountains of Italy. Similar spatial variability is evident in the response of southwestern European precipitation rates to onshore moisture advection during the negative winter phase of the NAO (Trigo et al. 2004). This consistency indicates that for this region geography and orography constrain local precipitation response to large-scale climate variability over the North Atlantic. Future study with higherresolution data for this region will better constrain the local precipitation response to ENSO variability. 

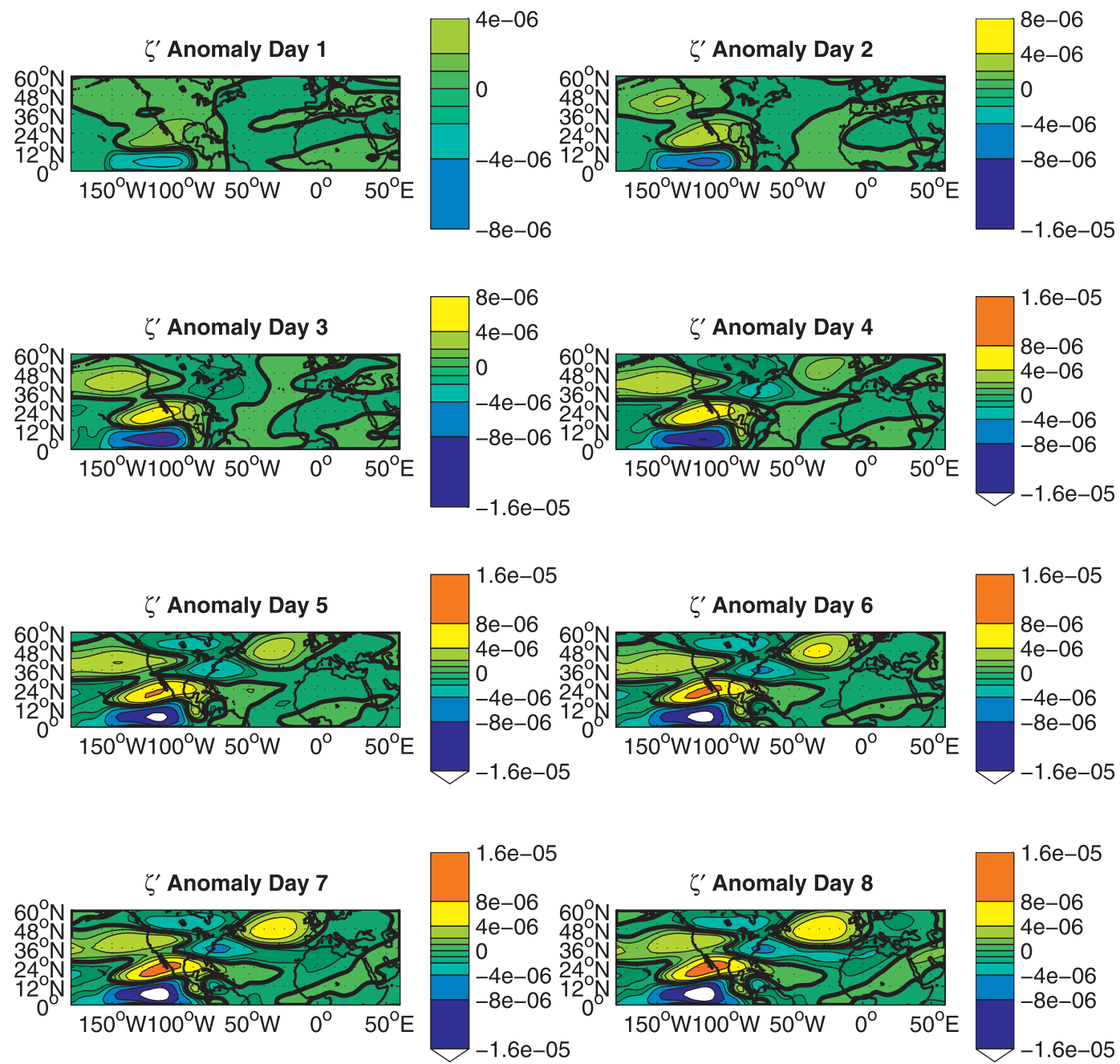

FIG. 11. Time integration solutions of the linearized barotropic vorticity equation linearized about SOND 200-mb reanalysis climatology and forced with divergence extending over $150^{\circ}-90^{\circ} \mathrm{W}$ and $0^{\circ}-10^{\circ} \mathrm{N}$, as in Fig. $10 \mathrm{~d}$. Vorticity solutions for the first 8 days of integration are shown. Contour intervals are irregular and as specified in the color bars. The zero contour is thickened.

Other processes also affect precipitation in the region. Previous work has shown that large-scale environmental conditions alter and interact with storm activity and tracking over the Atlantic, which then affects rainfall variability over southwestern Europe (Ulbrich et al. 1999; Saenz et al. 2001; Santos et al. 2009a,b). In this study, we have not explicitly explored how ENSO variability affects such transient wave activity. In fact, the linearized barotropic vorticity equation used to model the effect of ENSO on atmospheric conditions excludes baroclinic, nonlinear, and transient processes. Future study and simulation of the ENSO-SWEP teleconnection should include these additional processes. Possible decadal variability in the strength of this teleconnection should also be explored.
Not all El Niño events are alike (Krishna Kumar et al. 2006; Ashok et al. 2007); each El Niño produces a distinct spatial and temporal distribution of SST, rainfall, and upper-tropospheric divergence anomalies. The results presented here indicate that the variability of southwestern Europe September-December precipitation is linked in particular to contemporaneous changes of eastcentral equatorial Pacific SSTs and associated convective activity.

The atmospheric teleconnection described here provides a rapid link between conditions in the east-central equatorial Pacific and precipitation over southwestern Europe. Simulations with the linearized barotropic vorticity equation model indicate that the eastward-propagating Rossby wave train only takes a few days to reach the 
a) $\zeta^{\prime}$ solution; Sponge Layer at $270^{\circ} \mathrm{E}$

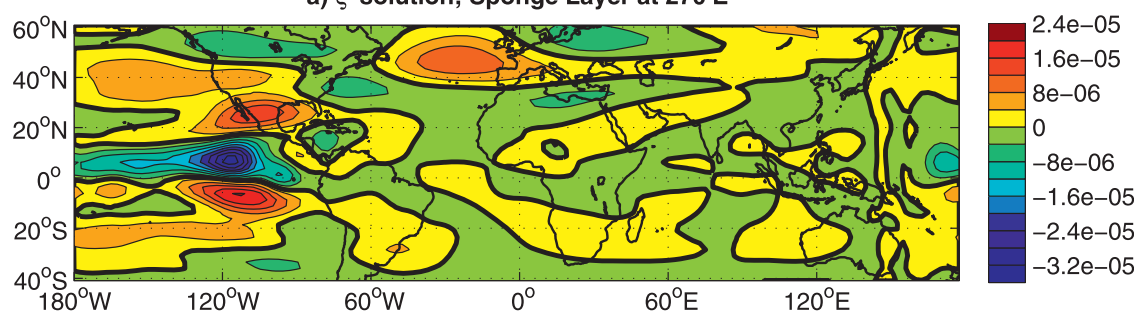

b) Sponge Layer Damping at $270^{\circ} \mathrm{E}$

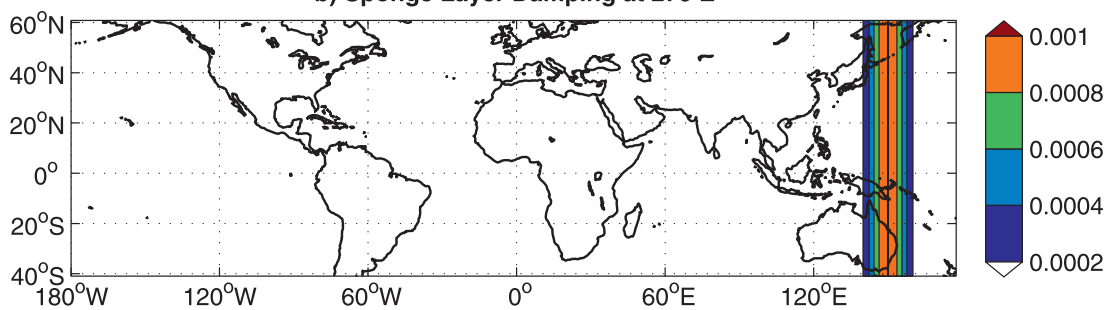

FIG. 12. Steady solution of the linearized barotropic vorticity equation linearized about SOND 200-mb reanalysis climatology with sponge damping. (a) Vorticity solution to forcing as shown in Fig. 9 b, and (b) sponge damping centered at $150^{\circ} \mathrm{E}$ are shown. Contour intervals are (a) $0.4 \times 10^{-5} \mathrm{~s}^{-1}$ and (b) $2.0 \times 10^{-4} \mathrm{~s}^{-1}$

North Atlantic from the Pacific (Fig. 11). Seven days after forcing initiation the vorticity dipole west of Iberia is well developed and strengthening.

Previous analyses have found seasonal lead-lag associations between ENSO conditions and precipitation anomalies over the Mediterranean region (Rodo et al. 1997; Knippertz et al. 2003; Pozo-Vazquez et al. 2005). The atmospheric teleconnection presented here is too rapid to enable a seasonal lag without some intermediary or alternate mechanism. One such mechanism might be the seasonal persistence of ENSO. That is, associations between boreal autumn ENSO conditions and boreal winter precipitation over Iberian (e.g., Pozo-Vazquez et al. 2005) may merely reflect this persistence in the $\mathrm{Pa}-$ cific from one season to the next. Our findings suggest that medium-range climate forecasts of SWEP might be constructed using seasonal ENSO predictions and the atmospheric teleconnection described here.

Numerous studies have demonstrated statistical associations between Iberian region precipitation and ENSO (Rodo et al. 1997; Mariotti et al. 2002; Park 2004; Rimbu et al. 2001; Pozo-Vazquez et al. 2005; Vicente-Serrano 2005; Sordo et al. 2008). Here, we have described the dynamic mechanism responsible for this teleconnection during boreal autumn and winter. By further understanding the dynamics underpinning teleconnections between ENSO and the Mediterranean climate, projections of how climate and weather for this region may change in the future may be improved. Similar dynamical studies of ENSO teleconnections with other regions of the Mediterranean will be undertaken in the future.
Acknowledgments. This work was funded by NSF Climate and Large-Scale Dynamics Grant 0917609.

\section{REFERENCES}

Adler, R. F., and Coauthors, 2003: The version 2 global precipitation climatology project GPCP monthly precipitation analysis (1979-present). J. Hydrometeor., 4, 1147-1167.

Ashok, K., S. K. Behera, S. A. Rao, H. Y. Weng, and T. Yamagata, 2007: El Niño Modoki and its possible teleconnection. J. Geophys. Res., 112, C11007, doi:10.1029/2006JC003798.

Branstator, G., 1983: Horizontal energy propagation in a barotropic atmosphere with meridional and zonal structure. J. Atmos. Sci., 40, 1689-1708.

Bretherton, C. B., C. Smith, and J. M. Wallace, 1992: An intercomparison of methods for finding coupled patterns in climate data. J. Climate, 5, 541-560.

Climate Prediction Center, cited 2009: North Atlantic Oscillation [Available online at http://www.cpc.ncep.noaa.gov/data/teledoc/ nao.shtml.]

Dai, A., and T. M. L. Wigley, 2000: Global patterns of ENSOinduced precipitation. Geophys. Res. Lett., 27, 1283-1286.

Eshel, G., and B. F. Farrell, 2000: Mechanisms of eastern Mediterranean rainfall variability. J. Atmos. Sci., 57, 3219-3232.

_ , and _ 2001: Thermodynamics of eastern Mediterranean rainfall variability. J. Atmos. Sci., 58, 87-92.

Hoskins, B. J., and K. Karoly, 1981: The steady response of a spherical atmosphere to thermal and orographic forcing. J. Atmos. Sci., 38, 1179-1196.

Janowiak, J. E., and P. Xie, 1999: CAMS OPI: A global satelliterain gauge merged product for real-time precipitation monitoring applications. J. Climate, 12, 3335-3342.

Jones, P. D., T. Jonsson, and D. Wheeler, 1997: Extension to the North Atlantic Oscillation using early instrumental pressure observations from Gibraltar and southwest Iceland. Int. J. Climatol., 17, 1433-1450. 
Kalnay, E., and Coauthors, 1996: The NCEP/NCAR 40-Year Reanalysis Project. Bull. Amer. Meteor. Soc., 77, 437-471.

Kaplan, A., M. Cane, Y. Kushnir, A. Clement, B. Blumenthal, and B. Rajagopolan, 1998: Analyses of global sea surface temperature 1856-1991. J. Geophys. Res., 103, 18 567-18 589.

Karagiannidis, A. F., A. A. Bloutsos, P. Maheras, and C. Sachsamanoglou, 2008: Some statistical characteristics of precipitation in Europe. Theor. Appl. Climatol., 91, 193-204.

Knippertz, P., U. Ulbrich, F. Marques, and J. Corte-Real, 2003: Decadal changes in the link between El Niño and springtime North Atlantic Oscillation and European-North African rainfall. Int. J. Climatol., 23, 1293-1311.

Krishna Kumar, K., B. Rajagopalan, M. Hoerling, G. Bates, and M. Cane, 2006: Unraveling the mystery of Indian monsoon failure during El Niño. Science, 314, 115-119.

Laita, M., and M. Grimalt, 1997: Vorticity and pressure anomalies in the western Mediterranean during El Niño/Southern Oscillation extremes. Int. J. Climatol., 17, 475-482.

Mariotti, A., N. Zeng, and K.-M. Lau, 2002: Euro-Mediterranean rainfall and ENSO-A seasonally varying relationship. Geophys. Res. Lett., 29, 1621, doi:10.1029/2001GL014248.

Paeth, H., and P. Friederichs, 2004: Seasonality and time scales in the relationship between global SST and African rainfall. Climate Dyn., 23, 815-837.

Paredes, D., R. M. Trigo, R. Garcia-Herrera, and I. F. Trigo, 2006 Understanding precipitation changes in Iberia in early spring: Weather typing and storm-tracking approaches. J. Hydrometeor., 7, 101-113.

Park, S., 2004: Remote ENSO influence on Mediterranean sky conditions during late summer and autumn: Evidence for a slowly evolving atmospheric bridge. Quart. J. Roy. Meteor. Soc., 130, 2409-2422.

Pozo-Vazquez, D., S. R. Gamiz-Fortis, J. Tovar-Pescador, M. J. EstebanParra, and Y. Castro-Deiz, 2005: El Niño-Southern Oscillation events and associated European winter precipitation anomalies. Int. J. Climatol., 25, 17-31.

Price, C., L. Stone, A. Huppert, B. Rajagopalan, and P. Alpert, 1998: A possible link between El Niño and precipitation in Israel. Geophys. Res. Lett., 25, 3963-3966.

Rimbu, N., H. L. Treut, S. Janicot, C. Boroneant, and C. Laurent, 2001: Decadal precipitation variability over Europe and its relation with surface atmospheric circulation and sea surface temperature. Quart. J. Roy. Meteor. Soc., 127, 315-329.

Rodo, X., E. Baert, and F. A. Comin, 1997: Variations in seasonal rainfall in southern Europe during present century: Relationships with the North Atlantic Oscillation and the El NiñoSouthern Oscillation. Climate Dyn., 13, 275-284.

Rogers, J. C., 1997: North Atlantic storm track variability and its association to the north Atlantic oscillation and climate variability of northern Europe. J. Climate, 10, 1635-1647.

Ropelewski, C. F., and M. S. Halpert, 1987: Global and regional scale precipitation patterns associated with the El NiñoSouthern Oscillation. Mon. Wea. Rev., 115, 2352-2362.

Saenz, J., J. Zubillaga, and C. Rodriguez-Puebla, 2001: Interannual variability of winter precipitation in northern Iberian Peninsula. Int. J. Climatol., 21, 1503-1513.
Santos, J. A., J. Corte-Real, and S. Leite, 2005: Weather regimes and their connection to the winter rainfall in Portugal. Int. J. Climatol., 25, 33-50.

—, J. G. Pinto, and U. Ulbrich, 2007: European winter precipitation extremes and large-scale circulation: a coupled model and its scenarios. Theor. Appl. Climatol., 87, 85-102.

— C. Andrade, J. Corte-Real, and S. Leite, 2009a: The role of large-scale eddies in the occurrence of winter precipitation deficits in Portugal. Int. J. Climatol., 29, 1493-1507.

—, J. Corte-Real, U. Ulbrich, and J. Palutikof, 2009b: On the development of strong ridge episodes over the eastern North Atlantic. Geophys. Res. Lett., 36, L17804, doi:10.1029/ 2009GL039086.

Shaman, J., and E. Tziperman, 2005: The effect of ENSO on Tibetan Plateau snow depth: A stationary wave teleconnection mechanism and implications for the South Asian monsoons. J. Climate, 18, 2067-2079.

- and - 2007: The summertime ENSO-North AfricanAsian jet teleconnection and implications for the Indian monsoons. Geophys. Res. Lett., 34, L11702, doi:10.1029/ 2006GL029143.

, S. K. Esbensen, and E. D. Maloney, 2009: The dynamics of the ENSO-Atlantic hurricane teleconnection: ENSO-related changes to the North African-Asian jet affect Atlantic basin tropical cyclogenesis. J. Climate, 22, 2458-2482.

Sordo, C., M. D. Frias, S. Herrera, A. S. Cofino, and J. M. Gutierrez, 2008: Interval-based statistical validation of operational seasonal forecast in Spain conditioned to El Niño-Southern Oscillation events. J. Geophys. Res., 113, D17121, doi:10.1029/ 2007JD009536.

Trigo, R. M., T. J. Osborn, and J. M. Corte-Real, 2002: The North Atlantic Oscillation influence on Europe: Climate impacts and associated physical mechanisms. Climate Res., 20, 9-17.

—, D. Pozo-Vazquez, T. J. Osborn, Y. Castro-Diez, S. GamizFortis, and M. J. Esteban-Parra, 2004: North Atlantic Oscillation influence on precipitation, river flow and water resources in the Iberian Peninsula. Int. J. Climatol., 24, 925-944.

Turkes, M., 1998: Influence of geopotential heights, cyclone frequency and the Southern Oscillation on rainfall variations in Turkey. Int. J. Climatol., 18, 649-680.

Ulbrich, U., M. Christoph, J. G. Pinto, and J. Corte-Real, 1999: Dependence of winter precipitation over Portugal on NAO and baroclinic wave activity. Int. J. Climatol., 19, 379-390.

Vicente-Serrano, S. M., 2005: El Niño and La Niña influence on droughts at different timescales in the Iberian peninsula. Water Resour. Res., 41, W12415, doi:10.1029/2004WR003908.

Xie, P. P., and P. A. Arkin, 1997: Global precipitation: A 17-year monthly analysis based on gauge observations, satellite estimates, and numerical model outputs. Bull. Amer. Meteor. Soc., 78, 2539-2558

Yakir, D., S. Lev-Yadun, and A. Zangvil, 1996: El Niño and tree growth near Jerusalem over the last 20 years. Global Change Biol., 2, 97-101.

Zhang, X., X. Wang, and J. Corte-Real, 1997: On the relationships between daily circulation patterns and precipitation in Portugal. J. Geophys. Res., 102, 13 495-13 507. 